\title{
Perspective effects in nondeontic versions of the Wason selection task
}

\author{
ALEXANDER STALLER, STEVEN A. SLOMAN, and TALIA BEN-ZEEV \\ Brown University, Providence, Rhode Island
}

\begin{abstract}
Perspective effects in the Wason four-card selection task occur when people choose mutually exclusive sets of cards depending on the perspective they adopt when making their choice. Previous demonstrations of perspective effects have been limited to deontic contexts-that is, problem contexts that involve social duty, like permissions and obligations. In three experiments, we demonstrate perspective effects in nondeontic contexts, including a context much like the original one employed by Wason $(1966,1968)$. We suggest that perspective effects arise whenever the task uses a rule that can be interpreted biconditionally and different perspectives elicit different counterexamples that match the predicted choice sets. This view is consistent with domain-general theories but not with domainspecific theories of deontic reasoning-for example, pragmatic reasoning schemas and social contract theory-that cannot explain perspective effects in nondeontic contexts.
\end{abstract}

Are the procedures that people use to reason domain specific or domain general? Much of the support for the view that reasoning is domain specific comes from work on the Wason selection task (WST; Wason, 1966, 1968). A number of theories propose that people's reasoning in this task depends on whether the task uses deontic content or not-that is, whether it asks people to reason about a social rule concerning duty or obligation or some other kind of rule. One type of evidence that appears to suggest that deontic reasoning is special involves perspective effects, demonstrations that choice in the WST varies with the perspective adopted during task performance. With one exception (Fairley, Manktelow, \& Over, 1999), these demonstrations have been limited to deontic contexts (Gigerenzer \& Hug, 1992; Holyoak \& Cheng, 1995; Manktelow \& Over, 1991; Politzer \& Nguyen-Xuan, 1992). To account for these effects, theorists have posited that performing this task in a deontic context activates specialized domain-specific reasoning processes that elicit a different pattern of response than does reasoning in other contexts (e.g., Cheng \& Holyoak, 1985; Cosmides, 1989; Oaksford \& Chater, 1994).

The objective of this paper is to show that the "deontic" response pattern can be obtained in nondeontic contexts. Unlike Fairley et al. (1999), whose demonstration of nondeontic perspective effects concerned conditional statements about causal relations, we aim to elicit perspective effects by choosing conditionals without regard to the type of relation they express, other than that it not be deontic. Such a result would suggest that Wason task performance can be attributed to a domain-general pro-

We thank Amit Almor, Philip Johnson-Laird, Ken Manktelow, David Over, and an anonymous reviewer for their comments on prior drafts. Correspondence should be addressed to A. Staller, Austrian Research Institute for Artificial Intelligence, Schottengasse 3, A-1010 Vienna, Austria (e-mail: alexs@ai.univie.ac.at). cedure. We propose, in agreement with existing domaingeneral theories, that perspective effects in both deontic and nondeontic contexts depend on the elicitation of counterexamples.

In the original abstract version of the WST, participants are presented with four cards. On one side of each card is a letter, and on the other side of the card is a number. Participants are then given a conditional rule of the form "If $p$ then q," for example, "If there is a vowel on one side of the card ( $p)$, then there is an even number on the other side (q)." The participants' task is to check whether the cards conform to this rule by choosing one or more cards to turn over. Each card has either $p$ or not$p$ on one side and either $q$ or not-q on the other. Participants are shown four cards, showing $p$, not-p, q, and not$q$, respectively. People tend to select the $p$ and $q$ cards or just the $\mathrm{p}$ card in this task.

However, people predominantly select the $p$ and not- $q$ cards for a few rules embedded in deontic contexts, where the rule is expressed as a social obligation or a right (see, e.g., Cheng \& Holyoak, 1985; Griggs \& Cox, 1982; Johnson-Laird, Legrenzi, \& Legrenzi, 1972). One example involves the "drinking-age rule" (Griggs \& Cox, 1982): "If a person is drinking beer then that person must be over 19 years of age." Participants were presented with four cards that showed "drinking beer," "drinking Coke," "22 years old," and " 16 years old," respectively. They were asked to assume the perspective of a police officer on duty who wants to determine whether the drinking-age rule has been violated. In contrast to most other versions of the WST, this context caused the majority of participants to select the $p$ and not-q cards: "drinking beer" and " 16 years old." Results of this sort have motivated theories that give a special place to deontic reasoning (e.g., Cheng \& Holyoak, 1985; Cosmides, 1989; Oaksford \& Chater, 1994).

But selection of the $p$ and not-q cards has been demonstrated in nondeontic contexts as well (Almor \& Sloman, 
1996; Green, 1995; Green \& Larking, 1995; Sperber, Cara, \& Girotto, 1995). For example, Almor and Sloman used the quality-control rule "If the product breaks then it must have been used under abnormal conditions" and found that people were significantly more likely to choose the $p$ and not- $q$ cards (the product broke and it was used under normal conditions) despite the clearly nondeontic but rather causal nature of the rule. This result may have occurred because the quality-control context is sufficiently familiar that it elicits counterexamples-products that are bad despite correct usage. These counterexamples have the right structure: They match the $p$ and not- $q$ cards.

Sperber et al. (1995) provided a "recipe" for creating nondeontic versions of the WST that lead to " $p$ and notq" selections, on the basis of relevance theory (Sperber \& Wilson, 1995). Relevance theory rests on two principles: The first (cognitive) principle states that human cognition is geared toward the maximization of relevance. Relevance increases with the cognitive effect resulting from the processing of information and decreases with the effort required to process it. The second (communicative) principle states that every utterance conveys the presumption that it is relevant enough to be worth the addressee's effort to process. The recipe consists in formulating a context in which knowing whether there are " $p$ and not- $q$ " cases (i.e., counterexamples) has a greater cognitive effect than knowing whether there are " $p$ and q" cases. Further, the processing effort for representing the combination of $p$ and not-q must be lower than the effort required to represent the combination of $p$ and $q$. For example, participants were told that the leader of a sect was accused of creating an elite group of "virgin-mothers." The leader claimed: "If a woman has a child she has had sex." In this context, " $p$ and not-q" cases (virginmothers) are easy to represent, and knowing whether there are virgin-mothers in the sect has a greater cognitive effect than knowing whether there are normal mothers. As predicted by relevance theory, participants predominantly selected the $\mathrm{p}$ ("has children") and not-q ("did not have sex") cards.

Green (1995; Green \& Larking, 1995) elicited "p and not-q" selections in nondeontic versions of the WST by using an "externalization procedure": First, participants had to identify the counterexample to the rule; in a second step, they were asked to identify all cards that could potentially instantiate this counterexample; then they made their selections. The experiments showed that identifying the combination of $p$ and not-q as the counterexample to the rule was necessary but not sufficient for the elicitation of " $p$ and not-q" selections. Only participants who identified the "p and not-q" counterexample in the first step and the $p$ and not-q cards in the second step reliably made " $p$ and not-q" selections.

A second type of evidence that has suggested that deontic reasoning is special, besides the high number of " $p$ and not-q" selections, involves perspective effects (Gigerenzer \& Hug, 1992; Holyoak \& Cheng, 1995; Manktelow
\& Over, 1991; Politzer \& Nguyen-Xuan, 1992). A perspective effect occurs whenever participants are induced to select either the $p$ and not-q pair of cards or the not-p and $q$ pair by varying the perspective from which they choose. For example, Manktelow and Over presented participants with the following rule, a statement made by a mother to her son: "If you tidy your room then you may go out to play." If participants were instructed to take the son's perspective and to check whether the mother violated the rule, they tended to select the $\mathrm{p}$ ("tidied the room") and not-q ("did not go out to play") cards. However, if participants were asked to take the mother's perspective and to check whether the son had violated the rule, they opted for turning the not-p ("did not tidy the room") and q ("went out to play") cards instead.

Perspective effects have been construed as evidence in favor of theories that assume special domain-specific deontic reasoning processes. To explain perspective effects, these theories assume that the interpretation of a social obligation or right can be reversed depending on the perspective the reasoner takes (such as pretending to be a child or a parent). The two major theories making this assumption are pragmatic reasoning schemas and social contract theory. These theories are described in more detail next.

\section{Pragmatic Reasoning Schemas}

Cheng and Holyoak (1985) proposed that reasoning on the WST is based on pragmatic reasoning schemas. A pragmatic reasoning schema is an abstract knowledge structure consisting of a generalized set of context-sensitive rules defined in relation to classes of goals. The pragmatic reasoning schemas assumed to underlie reasoning on deontic versions of the WST involve permission and obligation (Holyoak \& Cheng, 1995; Politzer \& Nguyen-Xuan, 1992). The permission schema is applied to all conditionals of the type "If an action is to be taken, then a precondition must be satisfied," and includes four rules:

Pl: If the action is to be taken, then the precondition must be satisfied.

P2: If the action is not to be taken, then the precondition need not be satisfied.

P3: If the precondition is satisfied, then the action may be taken.

P4: If the precondition is not satisfied, then the action must not be taken.

The obligation schema is applied to all conditionals of the type "If a precondition is satisfied, then an action must be taken," and includes the following rules:

$\mathrm{O} 1$ : If the precondition is satisfied, then the action must be taken.

O2: If the precondition is not satisfied, then the action need not be taken.

O3: If the action is to be taken, then the precondition may have been satisfied. 
O4: If the action is not to be taken, then the precondition must not have been satisfied.

Politzer and Nguyen-Xuan (1992) accounted for perspective effects in deontic contexts with a compound schema made of a permission and an obligation schema. Holyoak and Cheng (1995) generalized this account and related it to the concepts of rights and duties used in legal theory. People are assumed to focus on the interpretation of the rule that yields a definite conclusion of their own rights and duties. Consider the "day-off rule" (Gigerenzer \& Hug, 1992): "If an employee works on the weekend, then that person gets a day off during the week." The employee interprets the rule as an obligation for the employer and maps it onto rule O1: "If an employee works on the weekend, then the employer must grant a day off during the week." The employer interprets the rule as permission and maps it onto rule P3: "If an employee works on the weekend, then that person may take a day off during the week." People are assumed to check the cards corresponding to the antecedents of the rules that are deterministic - that is, the rules that contain "must" in the consequent. The employee will therefore check the cards corresponding to the antecedents of $\mathrm{O} 1$ and $\mathrm{O} 4$ ("worked on the weekend" and "did not get a day off"), whereas the employer will select the cards corresponding to the antecedents of P1 and P4 ("gets a day off" and "did not work on the weekend").

\section{Social Contract Theory}

Social contract theory (Cosmides, 1989) proposes that people have a domain-specific module for reasoning in situations of social exchange. The main idea is that an environment in which individuals cooperate for mutual benefit leads to the development of social contracts where each individual has to pay a cost in order to receive a benefit. These contracts give rise to Darwinian algorithms, such as the "look for cheaters" algorithm that is designed to expose individuals who take a benefit without paying the cost. Cosmides examined performance on the WST with rules that followed two general forms: the "standard social contract" ("If you take a benefit then you must pay a cost") and the "switched social contract" ("If you pay a cost then you take the benefit"). In the versions with the standard social contract, participants selected the $p$ and not-q cards, whereas in the versions with the switched social contract, participants tended to choose the not-p and $\mathrm{q}$ cards. The selected cards always corresponded to "takes the benefit" and "did not pay the cost," the constituent parts of the "look for cheaters" algorithm.

Gigerenzer and Hug (1992) offered social contract theory as an explanation for perspective effects with deontic rules by showing that a perspective shift occurs only if the rule is a contract with bilateral cheating options, such as the day-off rule, where both parties involved (e.g., employer and employee) can be cheated. They took this finding as evidence that the "look for cheaters" algorithm is critical for the emergence of perspective effects. Thus, like pragmatic reasoning schemas, so- cial contract theory explains perspective effects by appealing to specialized deontic reasoning processes.

\section{An Example-Based Account of Perspective Effects}

A different explanation of perspective effects is more general and predicts that perspective effects can be obtained in nondeontic contexts as well as deontic ones. It is that perspective effects occur whenever a rule (deontic or not) has a biconditional interpretation, and different perspectives elicit different counterexamples (see Pollard, 1982). The rule "If $p$ then $q$ " interpreted as a biconditional has two counterexamples: a "p and not-q" instance and a "not-p and q" instance. To generate perspective effects like those just discussed, one perspective would have to elicit the "p and not-q" counterexample and the other the "not-p and q" counterexample.

All deontic rules for which perspective effects have been observed can be interpreted biconditionally. For example, the rule "If you tidy your room then you may go out to play" usually implies "If you don't tidy your room then you may not go out to play." Geis and Zwicky (1971) called such a rule a promise with an "invited inference." Promises are not the only kind of conditionals with an invited inference, however. Geis and Zwicky gave examples of nondeontic lawlike statements such as "If you heat iron in the fire then it turns red" (where the invited inference is that cold iron is not red).

We report three experiments to test the example-based account of perspective effects. In each experiment, participants were given a version of the WST with a nondeontic conditional "If $p$ then q" that had an invited inference "If not $p$ then not q." Participants were divided into two conditions. In the first condition, participants were made aware of a potential exception to the rule in the form of " $p$ and not-q" (called the " $p$ and not-q" condition). In the second condition, participants were made aware of a potential exception to the rule in the form of "not-p and q" (called the "not-p and q" condition). Experiments 1 and 2 included rules with thematic nondeontic content, whereas Experiment 3 presented participants abstract rules, one of which was the original version used by Wason. Thus, we attempt to show the existence of perspective effects not only with nondeontic thematic materials, but also with an abstract version.

\section{EXPERIMENT 1}

In this version of the WST, we used a thematic nondeontic rule. The context was taken from the experiment by Sperber et al. (1995) mentioned above. Participants were cued to take the role of a journalist who wants to find out whether the leader of a sect is telling the truth. In our experiment, the leader is accused of treating a group of children in his sect with a hypnosis method that affects children's intellectual development. In both conditions the leader denies using any hypnosis methods and claims: "If a Hare Mantra child is at least 8 years old, then 
that child performs well on the 8-year intelligence test." This claim invites the inference "If a Hare Mantra child is younger than 8 years, then that child performs poorly on the 8-year intelligence test," given what people know about children's acquisition of intellectual abilities. In the " $p$ and not-q" version, the hypnosis method has detrimental effects on intellectual development, whereas in the "not-p and q" version, it increases children's intellectual abilities, but negatively influences their personality development. The prediction was that participants in the two conditions would select opposing card pairs, resulting in a perspective effect.

\section{Method}

Participants. Forty-eight undergraduate students at Brown University served as unpaid volunteers after a class on cognitive development.

Materials, Design, and Procedure. Participants were randomly assigned to either the " $p$ and not- $q$ " condition or the "not-p and $q$ " condition and were told to work at their own pace. The "p and notq" version read as follows (contrary to the actual questionnaires, the parts that differ between the two conditions are emphasized):

Research on hypnosis has shown the following: A special hypnosis method, originally intended as a psychotherapy method for children. has turned out to have extremely detrimental effects on children's intellectual development. Even 12-vear-olds who have been treated with this hypnosis method perform poorly on the standard intelligence test that normal children do well on $b y$ the age of 8 . This test is called the "8-year intelligence test." The children treated with the hypnosis method remain severely mentally retarded throughout adulthood.

The head of the Hare Mantra (a very secret religious sect) has been accused of treating some children in his sect with this hypnosis method. His goal, it is claimed, is to create a group of subservient followers who do not understand the implications of his commands. He has been accused of selecting a group of children in his sect, so called "future servants," who undergo the hypnosis method. If this claim is true, then a characteristic feature of "future servants" is that, in contrast to other Hare Mantra children, they perform poorly on the 8-year-intelligence test when they are 8 to 12 years old.

The head of the Hare Mantra denies using any hypnosis method. He claims:

"If a Hare Mantra child is at least 8 years old, then that child performs well on the 8-year intelligence test."

Imagine that you are a journalist and that you are preparing an article on the Hare Mantra. You learn that a psychological survey has been carried out in which the performance of the Hare Mantra children on the 8 -year intelligence test was examined. There is a rumor that some of the tested children might have been "future servants." You visit the psychologist who carried out the survey. He refuses to tell you what he discovered.

You realize that before you on the psychologist's desk are four individual information cards about Hare Mantra children examined in the psychological survey. However, these four cards are partially concealed by other papers (as shown below). Of two cards, one can only see the top, where you can find out whether the child is younger or older than 8 years. Of the other two cards, you can only see the bottom, where you see whether the child performs well or poorly on the 8-year intelligence test. You are determined to take advantage of a moment in which the psychologist turns his back to uncover the papers and to learn more.

Indicate (by circling) the card or cards that you should uncover in order to find out whether what the head of the Hare Mantra claims is true, as far as these four children are concerned. Indicate only the card or cards that it would be absolutely necessary to uncover.

Participants were then shown a figure with four cards, each with either its top or bottom showing. Each card showed one of $\mathrm{p}$ ( 10 years), not-p ( 6 years), $q$ (performs well), and not-q (performs poorly).
The "not-p and q" version was identical except for the first two paragraphs and one sentence in the fourth paragraph. The first two paragraphs read as follows:

Research on hypnosis has shown the following: A special hypnosis method, which is effective only in childhood, increases children's intellectual abilities enormously. Even 3-year-olds who have been treated with this hypnosis method perform well on the standard intelligence test that normal children do well on not until the age of 8 . This test is called the "8-year intelligence test." But the hypnosis method has an extremely detrimental effect on the personality of the treated children. They lose their willpower and their ability to make independent decisions.

The head of the Hare Mantra (a very secret religious sect) has been accused of treating some children in his sect with this hypnosis method. His goal, it is claimed, is to create a group of highly intelligent, but weak-willed people he can use as leaders of future suborganizations of the sect. He has been accused of selecting a group of children in his sect, so called "future leaders," who undergo the hypnosis method. If this claim is true, then a characteristic feature of "future leaders" is that, in contrast to other Hare Mantra children, they perform well on the 8 -year-intelligence test when they are 3 to 7 years old.

The differing sentence in the fourth paragraph read:

There is a rumor that some of the tested children might have been "future leaders."

\section{Results and Discussion}

Table 1 shows the frequencies of the different patterns of card selections for the two conditions. Approximately the same number of people chose the $p$ and not-q cards in the two conditions. Only $8 \%$ in the "p and not-q" condition selected the $p$ and not-q cards, whereas no participant in the "not-p and q" condition did. The difference between conditions was more substantial with respect to the "not-p and q" selections; 10 people made this selection in the "not-p and $q$ " condition and none did in the " $p$ and not-q" condition. Fisher's Exact Test revealed that the interaction was significant: The chance of observing a contingency table more unbalanced than this one is only .015 .

The number of " $p$ and not-q" selections in the " $p$ and not-q" condition was not greater than that usually observed in the standard abstract task. However, it is striking that $50 \%$ of the participants in the "p and not-q" condition selected either the $p$ card or the not-q card. The high number of not-q selections is unusual.

Although there was not a clean shift from selecting the "p and not-q" combination to selecting the "not-p and q" combination, there was a significant effect with respect to the marginal card selection frequencies (Table 2). The differences between the two conditions were significant for all four cards $\left[\chi^{2}(1)=14.72, p<.0005\right.$ for the $p$ card; $\chi^{2}(1)=12.34, p<.0005$ for the not-p card; $\chi^{2}(1)=$ $8.39, p<.005$ for the $q$ card; $\chi^{2}(1)=4.27, p<.05$ for the not-q card]. This result is as predicted.

Table 1

Card Selection Frequencies on the Hare Mantra Problem From Experiment 1

\begin{tabular}{lccccccccc} 
& \multicolumn{1}{c}{ Card Selections } \\
\cline { 2 - 9 } Condition & $\begin{array}{c}\mathrm{p} \text { and } \\
\text { not- } \mathrm{q}\end{array}$ & $\begin{array}{c}\text { not- } \mathrm{p} \\
\text { and } \mathrm{q}\end{array}$ & $\mathrm{p}$ & not- $\mathrm{p}$ & $\mathrm{q}$ & not- $\mathrm{q}$ & $\mathrm{p}$ and $\mathrm{q}$ & Other \\
\hline $\mathrm{p}$ and not- $\mathrm{q}$ & 2 & 0 & 7 & 0 & 0 & 5 & 3 & 7 \\
not-p and $\mathrm{q}$ & 0 & 10 & 2 & 3 & 2 & 1 & 1 & 5 \\
\hline
\end{tabular}


Table 2

Marginal Card Selection Frequencies on the Hare Mantra Problem From Experiment 1

\begin{tabular}{ccccc} 
& \multicolumn{4}{c}{ Card Selections } \\
\cline { 2 - 5 } Condition & $\mathrm{p}$ & not- $\mathrm{p}$ & $\mathrm{q}$ & not- $\mathrm{q}$ \\
\hline p and not- $\mathrm{q}$ & 16 & 4 & 6 & 13 \\
not-p and $\mathrm{q}$ & 3 & 16 & 16 & 6 \\
\hline
\end{tabular}

The absence of " $p$ and not- $q$ " responses in the " $p$ and not-q" condition is surprising. This result contradicts Sperber et al.'s (1995) finding on the "virgin-mother" rule. Their rule, however, differs from the future-servants rule in the present experiment in that the term "virgin-mother" is composed of two words whose meaning can be mapped directly onto the $p$ and not- $q$ cards. In the present experiment, greater processing effort would be required to represent "p and not-q" cases.

The findings by Green (1995; Green \& Larking, 1995) also suggest a reason for the low number of " $p$ and notq" selections. Many participants who identified the combination of $p$ and not- $q$ as the counterexample to the rule may have identified and selected only one card that could provide this counterexample. This would explain the unusually high number of not-q selections in the "p and not-q" condition. Green's externalization procedure - explicitly identifying all cards that could show a counterexample-may have resulted in a higher number of " $p$ and not-q" selections.

\section{EXPERIMENT 2}

The Hare Mantra rule in Experiment 1 is certainly not deontic, but its context may afford a deontic interpretation (i.e., negatively influencing children's development is a violation of societal norms). Therefore, Experiment 2 was designed to test whether the selection reversal can be observed in versions of the WST that are definitively not deontic. To design a context with no deontic implications, we constructed a scenario where a friend complains about the weather, saying, "If it's a weekday, then the sun is shining." The invited inference is "If it's a day on the weekend, then the sun is not shining" because the friend complains that the sun shines on weekdays but not on weekends. Social agreement cannot (unfortunately) change the weather, hence this rule cannot possibly be construed as deontic. Participants were given one of two counterexamples: "You seem to remember that last Monday it was raining" ("p and not-q") or "You seem to remember that last Sunday the sun was shining" ("not-p and q"). As in the first experiment, the hypothesis was that participants in the two conditions would select opposing card pairs, demonstrating the predicted perspective effect.

\section{Method}

Participants. Fifty-eight undergraduate students at Brown University served as unpaid volunteers after a class on statistics in psychology.
Materials, Design, and Procedure. Participants were randomly assigned to either the " $p$ and not-q" condition or the "not-p and q" condition and were told to work at their own pace. The " $p$ and not- $q$ " version read as follows:

A friend of yours complains about the weather, saying, "If it's a weekday, then the sun is shining."

You think your friend may be wrong because you seem to remember that last Monday it was raining. Circle the newspaper(s) below that you would need to turn over in order to conclusively verify whether your friend's rule is true or not for these four days.

The four newspapers are identified by what you can see on them.

Participants were then presented with a figure showing four cards, one showing $p$ (Monday), another not-p (Sunday), another $q$ (sunshine), and the last one not-q (rain). The "not-p and q" version was identical except that the third sentence read as follows:

You think your friend may be wrong because you seem to remember that last Sunday the sun was shining.

\section{Results and Discussion}

Table 3 shows the frequencies of different patterns of card selections for the two conditions. In the " $p$ and not$q$ " condition, $41 \%$ selected $p$ and not-q versus $14 \%$ of participants in the "not-p and q" condition. With respect to the "not-p and q" selections, $28 \%$ of participants in the "not-p and q" condition made this selection versus only one person in the " $p$ and not-q" condition. This interaction was significant at the .01 level according to Fisher's Exact Test. This pattern was also found in the marginal card selection frequencies (Table 4). The differences between the two conditions were in the predicted directions and were significant for two of the four cards $\left[\chi^{2}(1)=4.88, p<.05\right.$ for the $p$ card; $\chi^{2}(1)=3.53$, $p>.05$ for the not-p card; $\chi^{2}(1)=2.51, p>.05$ for the $q$ card; $\chi^{2}(1)=8.38, p<.005$ for the not-q card]. The results are consistent with our claim that perspective effects depend on the elicitation of counterexamples.

\section{EXPERIMENT 3}

The weather rule in Experiment 2 is nondeontic but is still thematic. Experiment 3 was conducted in order to

Table 3

Card Selection Frequencies on the Weather Problem from Experiment 2

\begin{tabular}{|c|c|c|c|c|c|c|c|c|c|}
\hline \multirow[b]{2}{*}{ Condition } & \multicolumn{9}{|c|}{ Card Selections } \\
\hline & $\begin{array}{l}p \text { and } \\
\text { not- } q\end{array}$ & $\begin{array}{l}\text { not }-\mathrm{p} \\
\text { and } \mathrm{q}\end{array}$ & $\mathrm{p}$ & not-p & $q$ & not-q & $\begin{array}{l}p \text { and } \\
\text { not-p }\end{array}$ & $\mathrm{p}$ and $\mathrm{q}$ & Other \\
\hline $\mathrm{p}$ and & 12 & 1 & 3 & 1 & 0 & 1 & 0 & 5 & 6 \\
\hline not-p and $q$ & 4 & 8 & 2 & 2 & 0 & 0 & 1 & 5 & 7 \\
\hline
\end{tabular}

Table 4

Marginal Card Selection Frequencies on the Weather Problem From Experiment 2

\begin{tabular}{ccccc}
\hline & \multicolumn{4}{c}{ Card Selections } \\
\cline { 2 - 5 } Condition & $\mathrm{p}$ & not- $\mathrm{p}$ & $\mathrm{q}$ & not-q \\
\hline p and not- $\mathrm{q}$ & 23 & 8 & 10 & 19 \\
not-p and $\mathrm{q}$ & 15 & 15 & 16 & 8 \\
\hline
\end{tabular}


test whether the selection reversal can be observed in versions of the WST that use abstract rules. This kind of evidence would show that deontic models are not general enough to account for all perspective effects.

\section{Method}

Participants. Sixty-four undergraduate students participating in the Brown summer session served as unpaid volunteers. Two participants indicated that they had encountered the WST before, and 10 others indicated that they had used knowledge of formal logic. These participants were omitted from the analyses, ensuring that the remaining participants were naive to the purposes of the present study.

Materials, Design, and Procedure. Two problems were constructed. In one problem the cards contained letters and numbers
(LN problem), whereas in the other problem they contained triangles and circles (TC problem). The "p and not-q" version of the LN problem is presented in Figure 1.

The initial claim that there were just two card types, showing either "p and q" or "not-p and not-q," was included to facilitate a biconditional interpretation of the rule. The "not-p and q" version was identical except that the Type C card description stated, "A card of type $\mathrm{C}$ shows a consonant at the top and an even number at the bottom"; the diagram was changed accordingly.

The TC problem was identical with the $\mathrm{LN}$ problem except that the rule was "If there is a large triangle at the top, then there is a large circle at the bottom." Throughout the problem, vowels were replaced by large triangles, even numbers by large circles, consonants by small triangles, and odd numbers by small circles. Geometric figures were portrayed on the cards.

In a psychology experiment, the experimenter presents the participant with four cards that are partially concealed. These cards are shown at the bottom of the page.

The experimenter explains: "Each of these four cards shows a letter at the top and a number at the bottom. You see just one half of each card. Further, each card is either of type A or type B. A card of type A shows a vowel at the top and an even number at the bottom, and a card of type B shows a consonant at the top and an odd number at the bottom."

Type A

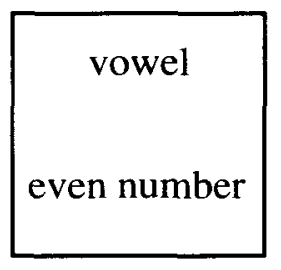

Type B

consonant

odd number

The experimenter asks the participant to formulate a rule that best expresses the relationship between the letters and numbers on all four cards. The participant suggests the rule:

"If there is a vowel at the top, then there is an even number at the bottom."

Then the experimenter says:

"The information I gave you before might be wrong. It is possible that one card is of type C. A card of type C shows a vowel at the top and an odd number at the bottom."

Type C

vowel

odd number

Circle only the card or cards you now regard as absolutely necessary to uncover in order to determine whether the participant's rule is true or false.
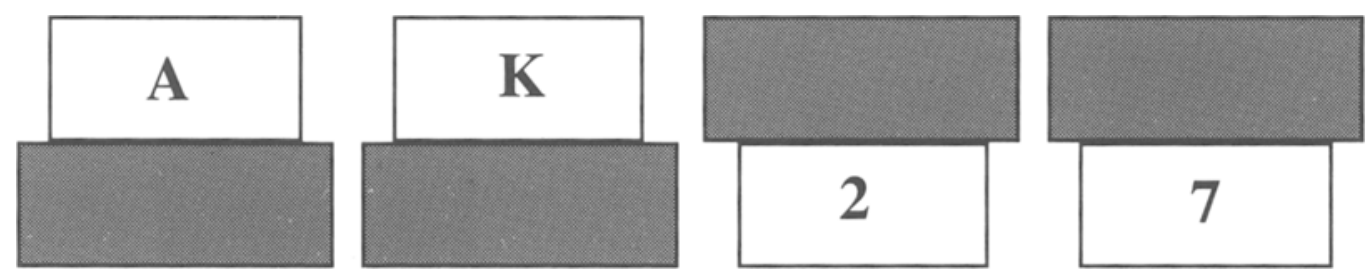

Figure 1. The "p and not-q" version of the LN problem (letters and numbers) from Experiment 3. 
Participants were randomly divided into two groups. One group was presented with the "p and not-q" version of the LN problem and the "not-p and q" version of the TC problem; the other group was presented with the complementary versions of the two problems. The order of the problems was counterbalanced. Participants were told to work on the problems in the given order at their own pace.

\section{Results and Discussion}

Table 5 shows the selection patterns on the $\mathrm{LN}$ problem and Table 7 presents the patterns on the TC problem. In both cases, the predicted interaction was obtained. In the "p and not-q" condition, $50 \%$ and $58 \%$ selected $p$ and not$q$ versus $3 \%$, and $0 \%$ of participants in the "not-p and q" condition, for the $\mathrm{LN}$ and TC problems, respectively. With respect to the "not-p and q" selections, 54\% and 31\% in the "not-p and q" condition made this selection for the two problems, respectively. Nobody in the " $p$ and not-q" condition chose the not-p and $q$ cards. These interactions were both significant at the .0001 level according to Fisher's Exact Tests. This pattern was also found in the marginal card selection frequencies (Tables 6 and 8). The differences between the two conditions were significant for all four cards, in both the LN and TC problems, and in the predicted directions [LN problem (Table 6$), \chi^{2}(1)=$ $17.33, p<.0001$ for the $\mathrm{p}$ card; $\chi^{2}(1)=25.53, p<.0001$ for the not-p card; $\chi^{2}(1)=19.66, p<.0001$ for the q card; $\chi^{2}(1)=11.70, p<.001$ for the not-q card. TC problem (Table 8), $\chi^{2}(1)=20.17, p<.0001$ for the $\mathrm{p}$ card; $\chi^{2}(1)=$ $15.83, p<.0001$ for the not-p card; $\chi^{2}(1)=9.03, p<.005$ for the $\mathrm{q}$ card; $\chi^{2}(1)=26.33, p<.0001$ for the not-q card].

These results show that thematic material is not necessary for the elicitation of perspective effects in nondeontic contexts. Perspective effects can also arise for rules as abstract as the original one employed by Wason (1966, 1968). In addition, our results imply that many participants who selected the $p$ and not-q cards on one problem selected the not-p and q cards on the other problem. Their choices depended only on the counterexamples elicited in the problem descriptions.

Table 5

Card Selection Frequencies on the LN Problem From Experiment 3

\begin{tabular}{lccccccccc}
\hline & \multicolumn{7}{c}{ Card Selections } \\
\cline { 2 - 9 } Condition & $\begin{array}{c}\mathrm{p} \text { and } \\
\text { not- } \mathrm{q}\end{array}$ & not-p & and $\mathrm{q}$ & $\mathrm{p}$ & not-p & $\mathrm{q}$ & not- $\mathrm{q}$ & $\mathrm{p}$ and $\mathrm{q}$ & Other \\
\hline $\mathrm{p}$ and not-q & 13 & 0 & 7 & 1 & 1 & 3 & 0 & 1 \\
not-p and $\mathrm{q}$ & 1 & 14 & 3 & 4 & 1 & 1 & 0 & 2 \\
\hline
\end{tabular}

Note-LN, letters and numbers.

Table 6

Marginal Card Selection Frequencies on the LN Problem From Experiment 3

\begin{tabular}{crccc}
\hline & \multicolumn{4}{c}{ Card Selections } \\
\cline { 2 - 5 } Condition & $\mathrm{p}$ & not-p & $\mathrm{q}$ & not- $\mathrm{q}$ \\
\hline $\mathrm{p}$ and not- $\mathrm{q}$ & 21 & 2 & 1 & 16 \\
not-p and $\mathrm{q}$ & 6 & 20 & 16 & 4 \\
\hline
\end{tabular}

Note-LN, letters and numbers.
Table 7

Card Selection Frequencies on the TC Problem From Experiment 3 Card Selections

\begin{tabular}{cccccccccc}
\hline & \multicolumn{8}{c}{ Card Selections } \\
\cline { 2 - 9 } Condition & $\begin{array}{c}\mathrm{p} \text { and } \\
\text { not- } \mathrm{q}\end{array}$ & $\begin{array}{c}\text { not-p } \\
\text { and } \mathrm{q}\end{array}$ & $\mathrm{p}$ & not-p & $\mathrm{q}$ & not- $\mathrm{q}$ & $\mathrm{p}$ and $\mathrm{q}$ & Other \\
\hline $\mathrm{p}$ and not- $\mathrm{q}$ & 15 & 0 & 6 & 0 & 1 & 2 & 0 & 2 \\
not-p and $\mathrm{q}$ & 0 & 8 & 4 & 5 & 3 & 1 & 2 & 3 \\
\hline
\end{tabular}

Note-TC, triangles and circles.

Table 8

Marginal Card Selection Frequencies on the TC Problem From Experiment 3

\begin{tabular}{crccc}
\hline & \multicolumn{4}{c}{ Card Selections } \\
\cline { 2 - 5 } Condition & $\mathrm{p}$ & not- $\mathrm{p}$ & $\mathrm{q}$ & not- $\mathrm{q}$ \\
\hline $\mathrm{p}$ and not-q & 23 & 1 & 3 & 19 \\
not-p and $\mathrm{q}$ & 7 & 14 & 13 & 1 \\
\hline
\end{tabular}

Note-TC, triangles and circles.

\section{GENERAL DISCUSSION}

Perspective effects do not require a deontic context. We have shown that perspective effects can be obtained with nondeontic thematic material as well as a version based on Wason's original abstract version of the WST. We conclude that perspective effects arise whenever different perspectives elicit different counterexamples to a rule with a biconditional interpretation. In our view, human reasoning does not give special status to rule violators. Rule violators are just one kind of counterexample for people reasoning about conditional rules.

These effects may have been mediated by participants' beliefs that the experimenters were particularly interested in the named counterexamples. Cards that partially matched counterexamples may have been chosen to comply with the perceived demands of the experiment. Doubtless, many participants did attempt to analyze the experimenter's construal of the problems and to respond accordingly. We have no problem with this analysis, except that it adds little to our analysis; it is just to say that participants performed the task as requested. Notice that the analysis can be applied equally well to experiments showing perspective effects in deontic contexts. Although the counterexample was not made explicit in those experiments, minimal inference made it readily available.

Our experiments do not show that domain-specific theories of deontic reasoning, such as pragmatic reasoning schemas and social contract theory, are wrong. However, their lack of generality does compromise their value in relation to theories that can explain perspective effects in deontic and nondeontic contexts. Unlike domain-specific theories, which rely on specifically deontic aspects of context, domain-general theories rely on general reasoning mechanisms and are consistent with the view that we have outlined. Such theories include mental models theory, relevance theory, and decision theory. 


\section{Mental Models Theory}

One of the key assumptions of the mental models approach to deductive inference (Johnson-Laird, 1983) is that the process of reasoning includes a search for counterexamples. According to Johnson-Laird and Byrne (1991), people do not have experience with counterexamples to abstract rules and thus form incomplete models that prevent them from selecting the $p$ and not- $q$ cards on the abstract version of the WST. However, "p and not-q" selections occur when models are "fleshed out" in a way that leads to the explicit representation of a counterexample. Deontic context is assumed to lead to this fleshing out. Perspective effects in deontic contexts occur for rules with a biconditional interpretation because one perspective leads to the explicit representation of the "p and not-q" counterexample, whereas the other perspective leads to the explicit representation of the "not-p and q" counterexample (Johnson-Laird \& Byrne, 1995).

However, deontic context is not necessary to flesh out mental models. Any available counterexample could be used for adding more complete models to the representation of the problem. Indeed, Johnson-Laird and Byrne (1995) predicted perspective effects for nondeontic rules with a biconditional interpretation, provided that the context were formulated in such a way that in one condition the mental model of the " $p$ and not- $q$ " counterexample is fleshed out, and in the other condition the mental model of the "not-p and q" counterexample. Our experiments have confirmed this prediction.

\section{Relevance Theory}

With respect to deontic rules, Sperber et al. (1995) argued that cases of rule violation are more relevant than permissible behavior. Thus, in order to maximize relevance, a deontic rule is interpreted as implicitly forbidding rule violation - that is, " $p$ and not-q" cases--and thus leads to the selection of the $p$ and not-q cards. Perspective effects occur with deontic rules because conditional rules expressing a contract between two parties make the rights and duties of one party explicit, but leave the rights and duties of the other party implicit. For the "day-off" rule "If an employee works on the weekend, then that person gets a day off during the week," this implicit content might be as follows: "If an employee gets a day off during the week, then that person must work on the weekend." This implicit content is the converse of the original rule and will be retrieved in order to maximize relevance if participants are cued into the perspective of the party whose rights and duties are left implicit. The implicit content is a deontic rule forbidding "not-p and q" cases and therefore leads to the selection of the not-p and q cards.

The concept of relevance can also be applied to the explanation of perspective effects in nondeontic contexts: Nondeontic rules interpreted as biconditionals also have an explicit and an implicit content, the implicit content being the invited inference "If not $p$ then not q." If the context makes the "p and not-q" counterexample rele- vant - the cognitive effect of knowing whether there are instances of it high, and the processing effort for representing it low-then participants retrieve the explicit content of the rule and select the $p$ and not- $q$ cards. If the context makes the "not-p and q" counterexample relevant, then participants retrieve the implicit content of the rule and select the not-p and q cards.

\section{Decision Theory}

Manktelow and Over (1991) proposed that perspective effects in deontic contexts are due to the subjective utilities of particular outcomes. For example, a mother values tidy rooms and therefore suffers a cost if her son goes out to play without having tidied up his room. The son, however, prefers the opportunity to play and suffers a cost if he tidies his room but is not allowed to go out. Assuming that the rule is "If you tidy your room then you may go out to play" and that people try to detect cases that entail a cost, the mother will try to detect instances of the "not-p and q" counterexample, whereas the son will try to detect instances of the " $p$ and not-q" counterexample. The result is the observed perspective effect.

Evans, Over, and Manktelow (1993) generalized this account. They proposed that people reason to support decisions and to achieve goals, and gave a decision-theoretic explanation of deontic reasoning. The standard normative principle of decision theory is that of subjective expected utility (SEU). The SEU of a decision is the sum of the utilities of the possible outcomes, with each utility weighted by the subjective probability of that outcome. Kirby (1994) proposed a model of the WST based on SEU.

Oaksford and Chater (1994) argued that expected utility can account for perspective effects. However, they restricted this utility-based analysis to deontic contexts and offered a different information-theoretic analysis of nondeontic contexts, which has no means to explain the results of our experiments. Therefore, our data present a problem for Oaksford and Chater's domain-specific account of perspective effects (for other problems, see Almor \& Sloman, 1996; Evans \& Over, 1996; Laming, 1996; Stanovich \& West, 1998).

The concept of utility is not restricted to the deontic domain. Thus, Evans and Over (1996) found it unsatisfactory that Oaksford and Chater (1994) used utility only for deontic tasks, and suggested that selections in the abstract task are affected by the subjective epistemic utility of data: "People's subjective epistemic utility is measured by the relevance of some data for them given their goals" (Evans \& Over, 1996, p. 358). The concept of subjective epistemic utility can be used to account for perspective effects in nondeontic contexts: These effects arise for nondeontic rules with a biconditional interpretation if in one condition the subjective epistemic utility of the " $p$ and not-q" counterexample is high, and in the other the subjective epistemic utility of the "not-p and q" counterexample is high.

Even though Evans and Over (1996) provided a possible normative standard for the assignment of subjec- 
tive epistemic utility embedded in a Bayesian framework, they did not offer a descriptive one. Nonetheless, we agree with their key point: Any general model of WST performance will require a construct as general as epistemic utility; the cost/benefit analysis that has been proposed to underlie deontic reasoning is insufficient.

\section{Complementarity of the Domain-General Theories}

The three domain-general theories described above are not mutually exclusive. Indeed, they complement each other by focusing on different aspects of the WST: Mental models theory is a theory of deduction and thus views the WST as a deductive reasoning task. Relevance theory focuses on pragmatic processes of language comprehension and suggests that WST performance depends on the interpretation of the rule. The decision-theoretic account emphasizes that the WST can be construed as a decisionmaking task.

Proponents of the theories have sometimes pointed out these complementarities. For example, Manktelow and Over (1991) explained perspective effects with a theory based on mental models, but extended with a representation of utilities. Similarly, Sperber et al. (1995) argued that maximizing relevance causes people to flesh out mental models. Finally, Evans and Over's (1996) characterization of subjective epistemic utility in terms of "relevance" (see above) suggests that decision theory and relevance theory can complement each other as well: Participants' utility judgments may depend on the relevancemaximizing interpretation of the rule.

In sum, our hypothesis that perspective effects depend on the elicitation of counterexamples is consistent with each of the three frameworks. Each provides a distinct but complementary motivation for our suggestion.

\section{Is Deontic Reasoning Different} From Other Forms of Reasoning?

Deontic reasoning is indeed different from other forms of reasoning in the sense that deontic logic is different. For example, a deontic conditional does not have the same truth conditions as the material conditional of propositional logic. The observation that Johnny's room is a mess and he is out playing does not falsify the rule "If Johnny doesn't clean his room, then he may not play outside." It just means that Johnny is disobedient. Such an observation would falsify the material conditional "If Johnny doesn't clean his room, then he does not play outside."

Further, modal operators used in different contexts support different inferences, a point noted by philosophers since Aristotle. For example, "must" used in the causal conditional "If the product breaks then it must have been used under abnormal conditions" (Almor \& Sloman, 1996) has different implications than the "must" used in the deontic conditional "If the product breaks then it must be reported immediately." Suppose that the product breaks. The causal conditional affords the inference that the product must have been and in fact was used under abnormal conditions. In contrast, it can be inferred from the deontic conditional that it must be reported immedi- ately, but not that it will be, because the rule might be violated. The causal "must p" logically implies p, but deontic "must p" does not.

Different modal operators exist to express necessity, possibility, certainty, probability, obligation, and so on, and each supports different inferences. This is why there are so many different modal logics. But little explanatory power would be gained by supposing that each modal logic corresponded to a domain-specific reasoning module in humans. But this is the natural extension of the modularity hypothesis suggested by Cosmides (1989). If logical differences between two operators implied different reasoning modules, then reasoning would involve a large number of modules indeed.

Reasoning in deontic and nondeontic domains feels different, and indeed is different, inasmuch as the domains support different logical relations. But pointing out these differences is a far cry from Cosmides's (1989) claim that there is a domain-specific module for deontic reasoning. The number and variety of logical differences between the two domains cannot be captured by a single reasoning module designed exclusively for the detection of cheaters.

Besides logical differences, there is a difference with respect to the elicitation of counterexamples in deontic and nondeontic contexts: Deontic contexts are noteworthy in the ease with which they elicit counterexamples. In our nondeontic contexts, we had to make counterexamples very explicit in order to obtain perspective effects. This difference is probably due to the relative availability of relevant knowledge in the two domains. People have extensive experience with counterexamples to deontic rules (i.e., cases of rule violation)-more experience than they have with counterexamples to nondeontic conditional rules. Hence, counterexamples may be more available when people are engaging in deontic reasoning than nondeontic reasoning because of domain-specific knowledge, but not because of domain-specific reasoning procedures.

\section{Conclusion}

The view that there are specialized deontic reasoning procedures has been based on two pieces of evidence: " $p$ and not-q" selections and perspective effects. Both of those pieces have now been undermined empirically. Earlier studies have demonstrated " $p$ and not-q" selections in nondeontic contexts (Almor \& Sloman, 1996; Green, 1995; Green \& Larking, 1995; Sperber et al., 1995). The present paper shows that perspective effects can arise in nondeontic contexts. This is some evidence that the same domain-general principles can govern reasoning in both deontic and nondeontic domains.

\section{REFERENCES}

Almor, A., \& Sloman, S. A. (1996). Is deontic reasoning special? Psychological Review, 103, 374-380.

Cheng, P. W., \& Holyoak, K. J. (1985). Pragmatic reasoning schemas. Cognitive Psychology, 17, 391-416.

Cosmides, L. (1989). The logic of social exchange: Has natural selec- 
tion shaped how humans reason? Studies with the Wason selection task. Cognition, 31, 187-276.

Evans, J. ST. B. T., \& Over, D. E. (1996). Rationality in the selection task: Epistemic utility versus uncertainty reduction. Psychological Review, 103, 356-363.

Evans, J. St. B. T., Over, D. E., \& Manktelow, K. I. (1993). Reasoning, decision making, and rationality. Cognition, 49, 165-187.

FaIRLEY, N., MankTELOW, K. I., \& OVER, D. E. (1999). Necessity, sufficiency, and perspective effects in causal conditional reasoning. Quarterly Journal of Experimental Psychology, 52A, 771-790.

GEIS, M. C., \& ZWICKY, A. M. (1971). On invited inferences. Linguistic Inquiry, 2, 561-566

Gigerenzer, G., \& HuG, K. (1992). Domain-specific reasoning: Social contracts, cheating and perspective change. Cognition, 43, 127-171.

GreEN, D. W. (1995). Externalization, counter-examples, and the abstract selection task. Quarterly Journal of Experimental Psychology, 48A, 424-446.

Green, D. W., \& Larking, R. (1995). The locus of facilitation in the abstract selection task. Thinking \& Reasoning, 1, 183-199.

GrIGgS, R. A.. \& Cox, J. R. (1982). The elusive thematic materials effect in the Wason selection task. British Journal of Psychology, 73. 407-420.

Holyoak, K. J., \& Cheng, P. W. (1995), Pragmatic reasoning with a point of view. Thinking \& Reasoning, 1, 289-313.

Johnson-Laird, P. N. (1983). Mental models. Cambridge: Cambridge University Press

Johnson-Laird, P. N., \& Byrne, R. M. J. (1991). Deduction. Hillsdale, NJ: Erlbaum.

Johnson-Laird, P. N., \& BYRne, R. M. J. (1995). A model point of view. Thinking \& Reasoning, 1, 339-350.
Johnson-Laird, P. N., LegrenZi, P., \& Legrenzi, M. S. (1972). Reasoning and a sense of reality. British Journal of Psychology, 63, 395-400.

KIRBY, K. N. (1994). Probabilities and utilities of fictional outcomes in Wason's four-card selection task. Cognition, 51, 1-28.

LAMING, D. (1996). On the analysis of irrational data selection: A critique of Oaksford and Chater (1994). Psychological Review, 103, 364-373.

MankTelow, K. I., \& OVER, D. E. (1991). Social roles and utilities in reasoning with deontic conditionals. Cognition, 39, 85-105.

OAKSFORD, M., \& ChATER, N. (1994). A rational analysis of the selection task as optimal data selection. Psychological Review, 101, 608-631.

Politzer, G., \& NGUyen-Xuan. A. (1992). Reasoning about conditional promises and warnings: Darwinian algorithms, mental models, relevance judgements or pragmatic schemas? Quarterly Journal of Experimental Psychology, 44, 401-412.

POLLARD, P. (1982). Human reasoning: Some possible effects of availability. Cognition, 12, 65-96

Sperber, D., Cara, F., \& Girotto, V. (1995). Relevance theory explains the selection task. Cognition, 57, 31-95.

Sperber, D., \& Wilson, D. (1995). Relevance: Communication and cognition (2nd ed.). Oxford: Blackwell.

Stanovich, K. E., \& WEST, R. F. (1998). Cognitive ability and variation in selection task performance. Thinking \& Reasoning, 4, 193-230.

WASON, P. C. (1966). Reasoning. In B. M. Foss (Ed.), New horizons in psychology (Vol. 1, pp. 135-151). Harmondsworth, U.K.: Penguin. WASON, P. C. (1968). Reasoning about a rule. Quarterly Journal of Experimental Psychology, 20, 273-281.

(Manuscript received October 27, 1998; revision accepted for publication March 30, 1999.) 